\title{
Effect of Rocker Sole Shoe on Foot Plantar Pressure: Is It Useful in Diabetic Patients?
}

\author{
Maryam Mirshahi* \\ Sina Hospital, Tehran University of Medical Sciences, Iran
}

Submission: April 14, 2017; Published: May 02, 2017

*Corresponding author: Maryam Mirshahi, Sina Hospital, Tehran University of Medical Sciences, Tehran, Iran, Tel: 989-120-761-153; Fax: 982163-485-53; Email: m.mirshahi2000@yahoo.com

\begin{abstract}
It is well known that high plantar pressures have a primary role in the pathogenesis of plantar ulcers in diabetic foot. Rocker sole shoes are designed to reduce pressure on high-risk areas on the plantar surface in the foot. The hypothesis is that the rocker nature of sole assists rolling of the body over the ground, controls joint motion and reduces the need for movement in the foot. Though the potential effectiveness of rocker shoes in pressure reduction is clear, but careful consideration need to be made. Since high-pressure areas depend on the condition of the foot and pressure varies with each patient, the design and prescribing of the rocker sole should be specified based on the patient's status.
\end{abstract}

Keywords: Diabetes mellitus; Rocker sole shoe; Plantar pressure; Diabetic foot; Diabetic Neuropathy; Footwear

\section{Introduction}

Diabetes mellitus is an epidemic chronic condition in worldwide [1]. There is considerable growth in the number of who have diabetes [2]. One of the most common complications of diabetes is neuropathy that affecting $50 \%$ to $70 \%$ of cases $[3,4]$. The loss of sensation in the foot due to peripheral neuropathy may often lead to muscle imbalance, delays in muscle activation patterns, abnormal gait and alterations of plantar pressure distribution pattern. Limited joint mobility and changes in the structure of the foot can also cause the gait abnormalities and elevated plantar pressure [4]. It is well known that high plantar pressures are a major risk factor in the pathogenesis of plantar ulcers in neuropathic foot [5]. Among persons with diabetes, the lifetime risk of developing an ulcer could be as high as $15-25 \%$ $[6,7]$. Ulcers are most often seen on high-pressure areas of the foot, especially on the metatarsal heads and toes [3].

According to the results of study by Merolli and Uccioli, pattern of plantar pressure distribution in healthy subjects demonstrated rear-foot contact in the heel strike phase, followed by a uniform distribution of load along the whole foot surface in the mid-stance phase. In the terminal-stance phase, the load was focused in the front of foot and evenly distributed along the arch of the metatarsal heads. During the toe-off phase, the load was transferred to the toes and finally the tip of the toe.In the diabetic neuropathic patient, interval between heel strike and toe-off was prolonged. In these patients, load was transferred very early from the rear to the forefoot.Load was increased in metatarsal heads in both magnitude and time. In the terminalstance and toe-off phases, weight was not transferred under big toe, further increasing load of the first metatarsal head [8].

Off-loading the forefoot is an important clinical aspect in people with diabetes who are at risk of developing a foot ulcer or who are healing an ulcer [5]. This Offloading essentially is achieved by redistribution of pressure to other foot regions [6]. Shoes adapted with rocker profiles are one of the most effective design of shoe that has been shown decrease the plantar pressure in people with diabetes mellitus. This type of shoe facilitate "rocking" of the foot from heel strike to toe-off, helping the tibia to rotate over the foot more easily and reducing both the range of foot joint motion and plantar pressure [2,910]. There are heel, ankle and forefoot rockers during normal gait cycle. It has been hypothesized that all of three rockers are unstable. The concept of "unstable shoe" such as rocker sole has been modeled after natural rockers of gait [11].

The general structure of the rocker shoes consist a curve surface in the front for reducing stress in the push-off phase and excessive bending of the metatarsal-phalangeal joint, a flat middle part for preserving stability and support in midstance and a curve in rear section for reducing impact force during heel 


\section{Current Research in Diabetes \& Obesity Journal}

strike [12]. A rocker sole shoe has three principle design features: apex angle, apex position and rocker angle [2]. The offloading properties of rocker soles depend on all of three features design. The offloading properties of rocker soles depend on all of three features. Three of the most commonly prescribed rocker soles are the toe-only, negative heel, and double rocker soles $[3,10]$. It is necessary to comprehend how each of the three design features influence plantar pressure.

The toe-only rocker shifts the loads of the weight-bearing proximal to the metatarsal heads and reduces toe stress on toeoff. During walking, the toe-only rocker prolongs midstance at the hindfoot and midfoot providing a stable midstance [3]. The negative heel rocker places the heel below or at the same level as the ball of the foot. The negative heel rocker through weight shifting to posterior helps to accommodate fixed ankle dorsiflexion $[3,13]$. Both type of negative heel and toe- only rocker are prescribed to decrease pressure on the forefoot with different biomechanics [3].

The double rocker decreases midfoot loading. In this type rocker, the midfoot does not touch the floor during midstance $[1,3]$. Double rocker effectively redistributes midfoot pressures [3]. This type rocker typically prescribed to relieve midfoot problems such as rocker bottom foot or a Charcot foot deformity [1]. In all kinds of rocker shoes, the mechanism of action is transfer of load from the forefoot to more proximal regions [6]. The hypothesis is that the rocker nature of sole assists rolling of the body over the ground, controls joint motion and reduces the need for movement in the foot [11]. The rocker sole shoes cause smooth progression through the stance phase of gait while restricting active dorsiflexion of the toes and therefore forefoot contribution in propulsion $[6,12]$. One of the biomechanical advantages of rocker-soled shoes is reducing plantar pressure on specific parts of the foot [12]. But the results of some studies have been shown that this pressure reduction is accompanied with increased pressure in the other areas of the foot. It has been reported the midfoot received most of the load transferred from the forefoot [14]. However, it seems rather than increasing the load, pressures are effectively distributed over a large midfoot surface area [6].

\section{Discussion}

There are a number of published studies that investigate the effect of rocker sole shoes on plantar pressures in diabetes patients [2,3-6,8-10,14,15]. Several studies have shown a percent reduction of plantar pressures of the forefoot ranging from $10 \%$ to $60 \%$, demonstrating efficacy of rocker soles for decreasing pressure of the forefoot [5]. Chapman et al suggest that an outsole design with a $95^{\circ}$ apex angle, apex position at $60 \%$ of shoe length and $20^{\circ}$ rocker angle may be an optimal choice for offloading different regions of the forefoot [2] . Other authors demonstrated different positions of rocker for optimal pressure relief [9].
Though a number of studies show the potential effectiveness of rocker shoes $[2,12,14]$ but comparison between the efficiency of rocker sole shoes is challenging for several reasons. These reasons include different equipment and methods for measuring of plantar pressure, diabetic patients who studied and the characteristics of the rocker sole (axis angle, apex position and the rocker angle) $[14,15]$. In fact, by adjusting in any design features, biomechanical effect of rocker will be change.

Walking comfort is also another subject that should be noted. Since comfort during walking with this shoe is relatively low, it may affect adherence and efficacy of intervention [6]. Despite these limitations, rocker sole shoes are effective offloading interventions if careful consideration to be made when prescribing such designs as to people with diabetes [12]. Since high-pressure areas depend on the condition of the foot and pressure varies with each patient, the design of the rocker sole should be specified based on the patient's status [3].

\section{Conclusion}

It is clear that rocker sole shoe is effective to reducing pressure in the diabetic foot, but each of the design may have a different effect on diabetic patients. In fact, no single configuration of rocker sole shoe has been demonstrated to be optimal for all subjects and in all areas of the forefoot. Depending on the patient, a specific sole can be prescribed to reduce plantar pressure. The toe-only, negative heel and double rocker soles can effectively reduce plantar pressures, helping to prevent of ulceration. It may be appropriate to encourage all people with diabetes to wear pressure reducing footwear for protect against plantar tissue damage.

\section{References}

1. Long JT, Klein JP, Sirota NM, Wertsch JJ, Janisse D, et al. (2004) Biomechanics of the double rocker sole shoe: Gait kinematics and kinetics. Conf Proc IEEE Eng Med Biol Soc 7: 5107-5107.

2. Chapman JD, Preece S, Braunstein B, Hohne A, Nester CJ, et al. (2013) Effect of rocker shoe design features on forefoot plantar pressures in people with and without diabetes. Clin Biomech 28(6): 679-685.

3. Brown D, Wertsch JJ, Harris GF, Klein J, Janisse D (2004) Effect of Rocker Soles on Plantar Pressures. Arch Phys Med Rehabil 85(1): 81-86.

4. Robinson CC, Balbinot LF, Silva MF, Achaval M, Zaro MA (2013) Plantar Pressure Distribution Patterns of Individuals with Prediabetes in Comparison with Healthy Individuals and Individuals with Diabetes. J Diabetes Sci Technol 7(5): 1113-1121.

5. Kavros SJ, Van Straaten MG, Coleman Wood KA, Kaufman KR (2011) Forefoot plantar pressure reduction of off-the-shelf rocker bottom provisional footwear. Clin Biomech (Bristol, Avon) 26(7): 778-782.

6. Bus SA, van Deursen RW, Kanade RV, Wissink M, Manning EA, et al. (2009) Plantar pressure relief in the diabetic foot using forefoot offloading shoes. Gait Posture 29(4): 618-622.

7. Waaijman R, Bus SA (2012) The interdependency of peak pressure and pressure-time integral in pressure studies on diabetic footwear: no need to report both parameters. Gait Posture 35(1): 1-5.

8. Merolli A, Uccioli L (2005) Plantar pressure distribution in patients with neuropathic diabetic foot. J Appl Biomater Biomech 3(1): 61-64. 


\section{Current Research in Diabetes \& Obesity Journal}

9. Hutchins S, Bowker P, Geary N, Richards J (2009) The biomechanics and clinical efficacy of footwear adapted with rocker profiles-Evidence in the literature. Foot (Edinb) 19(3): 165-170.

10. Bowling FL, Reeves ND, Boulton AJ (2011) Gait-Related Strategies for the Prevention of Plantar Ulcer Development in the High Risk Foot Curr Diabetes Rev 7(3):159-163.

11. Forghany S, Nester CJ, Richards B (2014) The effect of rollover footwear on the rollover function of walking. J Foot Ankle Res 6(1):24.

12. Lin SY, Su PF, Chung CH, Hsia CC, Chang CH (2017) Stiffness Effects in Rocker-Soled Shoes: Biomechanical Implications. PLoS One 12(1): e0169151.
13. Myers KA, Long JT, Klein JP, Wertsch JJ, Janisse D, et al. (2006) Biomechanical implications of the negative heel rocker sole shoe: gait kinematics and kinetics. Gait Posture 24(3): 323-330.

14. Praet SF, Louwerens JW (2003) The Influence of Shoe Design on Plantar Pressures in Neuropathic Feet. Diabetes Care 26(2): 441-5.

15. Bus SA, Valk GD, van Deursen RW, Armstrong DG, Caravaggi C (2008) The effectiveness of footwear and offloading interventions to prevent and heal foot ulcers and reduce plantar pressure in diabetes: a systematic review. Diabetes Metab Res Rev (24 Suppl 1): S162-S180.

\section{Your next submission with Juniper Publishers will reach you the below assets}

- Quality Editorial service

- Swift Peer Review

- Reprints availability

- E-prints Service

- Manuscript Podcast for convenient understanding

- Global attainment for your research

- Manuscript accessibility in different formats

( Pdf, E-pub, Full Text, Audio)

- Unceasing customer service

Track the below URL for one-step submission https://juniperpublishers.com/online-submission.php 